\title{
Conversations, Communication and Counseling Are Key Family Medicine Tactics to Improve Patient Health
}

\author{
Marjorie A. Bowman, MD, MPA, Dean A. Seehusen, MD, MPH, and \\ Anne Victoria Neale, $\mathrm{PhD}, \mathrm{MPH}$
}

This issue includes research on conversations, communication and counseling regarding depression treatment, the diagnosis of prediabetes, the topics of diversity and inclusion in medicine on Twitter, asthma treatment outcomes, muscle strengthening as an important form of exercise, multiple hospital readmissions, as well as after-visit summaries and advance care planning. ( $\mathrm{J}$ Am Board Fam Med 2019; 32:1-3.)

Men with a regular primary care physician responded to a hypothetical scenario in an online survey about treatment choices for depression. ${ }^{1}$ Men with positive attitudes toward their doctorpatient relationship were more likely to opt for pharmacotherapy and individual psychotherapy compared with a wait-and-see/no-treatment approach. Cosgrove et $\mathrm{al}^{2}$ provide suggestions on communicating with patients about the controversial issue of antidepressant effectiveness. Despite concerns, many patients report success with their antidepressant medicines and wish to continue long term.

Some good news that might be unexpected: Without additional intervention, patients notified of their prediabetes status improved compared with the comparison group who were also screened but did not receive a communication on their prediabetes status. ${ }^{3}$ This suggests the benefit of formalizing the diagnosis "prediabetes," as compared with suggesting a patient is "at risk for" diabetes. Similarly, in practice we (MB and DS) have seen patients notified of their prediabetes status make major lifestyle improvements. Thus, continue screening and keep counseling patients on their prediabetes status.

Social media plays a growing role in conversations about bias and discrimination in medicine. Discussions on diversity and inclusion are taking place on-

Conflict of interest: The authors are editors of the FABFM. line, including on Twitter, via specific hashtags. Mishori et $\mathrm{al}^{4}$ assessed selected hashtags and analyzed their reach, as well as whether and how health professional organizations publicized or amplified this emerging discourse on Twitter. The overall volume was average or below average when compared with all active Twitter users, however, the retweet percentage was very high $(60 \%)$ suggesting high levels of engagement. Medical societies' contributions to dissemination were very minor.

Clinicians are regularly reminded to follow specific treatment plans to improve asthma outcomes. Colborn et $\mathrm{al}^{5}$ found that the well-known Colorado asthma tool kit was associated with modest improvements in process measures-but not in the more important outcome measures. More work is obviously needed to identify methods to improve patient-centered asthma outcomes.

A personal history of military service has traditionally been associated with health benefits. This does not seem to be true for veterans of the more recent military conflicts, ${ }^{6}$ based on $>150,000$ responses to the National Health Interview Survey. Veterans $<70$ years of age reported higher rates of cardiovascular disease than nonveterans. The reasons are not clear. Is it changes in the levels or types of military conflicts, or characteristics of the individuals choosing to join the military, or some other cause? Crump et $\mathrm{al}^{7}$ make an important point that may relate to the health benefits of military service, but is certainly important for routine family med- 
icine exercise counseling: strengthening-not just aerobic-exercise can lead to longer, healthier lives.

Porter et $\mathrm{al}^{8}$ compared patients frequently readmitted to the hospital with those who were not. In additional to being older and with more severe illness, they found that certain diagnoses were more frequent in these patients, and discuss potential methods to prevention readmissions. They also found that patients in the high-frequency readmission group was dynamic and changed from year to year.

After-visit summaries (AVSs) are often inadequate communications because of missing information, or perhaps more importantly, because they were not in the patient's language, as noted by Mir et al. ${ }^{9}$ An additional editorial comment (MB): if the note is not complete before the patient leaves, the AVS is also often incomplete. For example, if the clinician or staff have to spend extra time after the visit to determine which medicine or specialist is covered by the insurance plan, there are delays that create an inaccurate AVS. Encouraging the use of a patient portal can help with some of these inadequacies, but usually does not address the language issue directly, nor adequately.

Advance care planning conversations are important to support patient-centered clinical decisions, yet patients often do not prepare advance directives, making substituted judgment decisions unrealistic. Tunzi and Ventres ${ }^{10}$ provide a case study to guide clinicians through these potentially difficult conversations, presented in a useful format of contrasting the clinical conversation with a reflection about how the physician can guide the conversation to a more productive outcome.

The $7 A B F M$ has published multiple articles on offices collaborating with patients on social determinants of health to improve outcomes. De Marchis et $\mathrm{al}^{11}$ take the opposite tactic: if the clinic does not have the resources to address social determinants of health, how does that affect the clinician? The answer is a definite negative.

The $7 A B F M$ also intermittently publishes studies based on the American Board of Family Medicine $(\mathrm{ABFM})$ certifying examinations. These articles are peer-reviewed in the same manner as other articles. This issue includes 2 such ABFM-related articles. First, Dai et $\mathrm{al}^{12}$ report on how family physicians evaluate the knowledge assessment and clinical simulation portions of the 16 self-assessment modules in the ABFM Maintenance of Cer- tification process (2006-2016). Second, Peterson et $\mathrm{al}^{13}$ demonstrate that the demographic data collected during ABFM examination registration provide valid and reliable descriptions of ABFM diplomate characteristics by initial certification and recertification status 8), providing a window into various demographic changes occurring among family physicians over time.

Seiverling et $\mathrm{al}^{14}$ found that teaching about benign skin lesions helps clinicians recognition of malignant lesions. Thus, instruction should include both benign and malignant lesions to help improve recognition between the 2 diagnoses.

To see this article online, please go to: http://jabfm.org/content/ 32/1/1.full.

\section{References}

1. Kealy D, Rice SM, Ferlatte O, Ogrodniczuk JS, Oliffe JL. Better doctor-patient relationships are associated with men choosing more active depression treatment. J Am Board Fam Med 2019;32:13-19.

2. Cosgrove L, Erlich D, Shaughnessy AF. No magic pill: a prescription for enhanced shared decisionmaking for depression treatment. J Am Board Fam Med 2019;32:6-9.

3. Owei I, Umekwe N, Ceesay F, Dagogo-Jack S. Awareness of prediabetes status and subsequent health behavior, body weight, and blood glucose levels. J Am Board Fam Med 2019;32:20-27.

4. Mishori R, Singh L, Lin KW, Wei Y. \#Diversity: Conversations on Twitter about women and black men in medicine. J Am Board Fam Med 2019;32:28-36.

5. Colborn KL, Helmkamp L, Bender BG, Kwan BM, Schilling LM, Sills MR. Colorado Asthma Toolkit implementation improves some process measures of asthma care. J Am Board Fam Med 2019;32:37-49.

6. Hinojosa R. Veterans' likelihood of reporting cardiovascular disease. J Am Board Fam Med 2019;32: 50-57.

7. Crump C, Sundquist K, Sundquist J, Winkleby MA. Exercise is medicine: Primary care counseling on aerobic fitness and muscle strengthening. J Am Board Fam Med 2019;32:103-107.

8. Porter M, Quillen D, Fe Agana D, et al. Are patients frequently readmitted to the hospital different from the other admitted patients? J Am Board Fam Med 2019;32:58-64.

9. Mir TH, Osayande A, Kone K, Bridges K, Day P. Assessing the quality of the After Visit Summary (AVS) in a primary-care clinic. J Am Board Fam Med 2019;32:65-68.

10. Tunzi M, Ventres W. A reflective case study in family medicine advance care planning conversations. J Am Board Fam Med 2019;32:108-114. 
11. De Marchis E, Knox M, Hessler D, et al. Physician burnout and higher clinic capacity to address patients' social needs. J Am Board Fam Med 2019; 32:69-78.

12. Dai M, Hagen M, Eden AR, Peterson LE. Physician Opinions about American Board of Family Medicine Self-Assessment Modules (2006-2016). J Am Board Fam Med 2019;32:79-88.
13. Peterson LE, Fang B, Phillips Jr. RL, Avant R, Puffer JC. The American Board of Family Medicine's data collection method for tracking their specialty. J Am Board Fam Med 2019;32:89-95.

14. Seiverling EV, Ahrns HT, Greene A, et al. Teaching benign skin lesions as a strategy to improve the Triage Amalgamated Dermoscopic Algorithm (TADA). J Am Board Fam Med 2019;32:96-102. 